\title{
Common Problems in Translation of Political Texts: The Case of English and Kurdish Languages
}

\author{
Rawand Sabah Ahmad ${ }^{1} \&$ Sami Hussein Hakeem Barzani ${ }^{2}$ \& Reman Sabah Meena ${ }^{3}$ \& Hewa \\ Fouad $\mathrm{Ali}^{4}$ \\ ${ }^{1,2,3,4}$ English Language Teaching Department, Tishk International University, Erbil, Iraq \\ Correspondence: Sami Hussein Hakeem Barzani, Tishk International University, Erbil, Iraq. \\ Email: sami.hussein@tiu.edu.iq
}

DOI: $10.53103 /$ cjlls.v1i2.14

\begin{abstract}
This study investigated and examined the problems pertaining to the translation of political texts. It intends to deal with the main translation difficulties and problems emerging in the process of translation of political texts from English to Kurdish Language. Concerning theoretical background, the study followed the Nord's classification of translation problems (1997): pragmatic, cultural, linguistic and text-specific issues, then the study reviews the relevant literature to address certain issues such as the definitions of translation, approaches to translation, specialized translation, translation problems, features of political language, and translation and political language. This is followed by a brief presentation of the methodology of this research. The study concludes that there are no specific methods in translating political texts due to the fact that translation is not only a practical process that employs translation techniques, but also an issue of comprehending cultural, historical and political situations and overtones.
\end{abstract}

Keywords: Translation, Translation Problems, Political Language, Political Texts

\section{Introduction}

Political texts are very different from other texts as they "are a part and/or the results of political events", and they are historically and culturally produced in which politics is the main subject matter (Schäffner, 2000, p. 133). Translating political texts is not a straightforward process, it is challenging and problematic for translators since texts belonging to the political field are considered as specialized texts which include specific terms, expressions, complex grammatical structures, and more importantly overtones.

The problem that this study confronts and attempts to shed light on is the difficulties and problems that arise in translating political texts. From this perspective, this problem raises the research question of the study, namely 'What are the main problems encountered by translators in the translation of political texts?'. The 
principal objective of the present research is to examine the difficulties coming up in political texts that are translated from one language into another. This study is a qualitative research in which a qualitative method is used to gather the necessary information for the analysis of the research. The tool which is utilized is document analysis since it is an easy way and more relevant to the present study for obtaining information. The study investigates certain important aspects of the translation problems of the political texts that have not been dealt with properly, specifically in the English to Kurdish translation texts.

\section{Definitions of Translation}

Many definitions of 'translation' have been suggested by many translation scholars and theoreticians. Based on their perspectives of character, purpose, object and role, they described the concept of translation (Schäffner, 2000).

One of the earlier efforts was made by Nida $(1964,2004$, p. 3) who defines translation as a scientific subject and illustrates that "the transference of a message from one language to another is a valid subject for the scientific description". In this attempt, he suggests the concept of dynamic equivalent and describes translation as "the closest natural equivalent of the source-language message, first in terms of meaning and secondly in terms of style" (p.12).

Catford (1965) explains the notion of translation and points out that this notion is perceived as "the replacement of textual material in one language (Source Language) by "equivalent" material in another language (Target Language)". For him, the main important point in the translation process is the concept of equivalence between the original and the target language. In other words, the target text should be equivalent to its source text in terms of meaning.

In a recent attempt, Bassnett $(1980,1991,2002)$, working within the field of cultural studies and approach to translation, postulates that translation should not be considered only as a type of whole linguistic activity, it should also be determined as a kind of communication within and among cultures. More specifically, translation is more a cross-cultural activity rather than a simple linguistic transfer. Furthermore, she also mentions that the cultural considerations should be given more attention in the translation activity, precisely in view of equivalence of translation text and the original text.

Lastly, from the perspective of the functionalist approaches to translation, "translations are generally seen as fulfilling functions quite different to those of STs, since they are for a fundamentally different audience, in a new culture situation" (Pym, 2009, p. 4). In this way, when the clients have several aims, one source text can be translated in different ways. In other words, for each scoop, one translation is produced. What is more, the concept of equivalence is not completely undervalued in 
the functionalism theory of translation, but it is reduced to one possibility (Pym, 2009). In this theory, when there is a strong similarity between the purpose of the production of the original text and the translation text, the equivalence in translation is achieved.

It is obvious from the above definitions that translation theorists and scholars have different opinions about what translation is and how it can be carried out. This controversy stems from the fact that theorists understand translation based on that theory of translation they are interested in. As result, several translation theories have been introduced to the translation studies field up to now.

\section{Approaches to Translation}

The exploration of the concept of translation is not old, it dates back to almost $70-80$ years ago. Since the mid of the last century, several theories and approaches have been proposed in order to illustrate how translation process should be carried out. Translation theories and approaches have benefited from other fields such as linguistics, cultural studies, philosophy and literature (Hatim \& Munday, 2004). As a result, translation has become a highly diversified area consisting of certain theories and methods, in which each of them looks at the notion of translation in a specific way (Omer, 2016). In this section, some of the theories are discussed briefly.

One of the primitive theories of translation is the linguistic approach which defines translation from the angle of linguistics. It highlights and emphasizes on the importance of equivalence between the source text and the target text in terms of from and content. Thus, accordingly, form and content play a vital role in the success of the translation process (Munday, 2012).

Later, some translation theorists (e.g., Vermeer, 1996 \& Nord, 1997) define translation as aim or purpose in a theory which is known as functionalism theory of translation. These scholars postulate that there should be a purpose for translating a text (Munday, 2012). Translation as a purpose is the main contribution of this theory to the translation field.

Some other theories and trends have appeared since the 1980s. These theories undervalue the field of linguistics in their understanding of the concept of translation. Cultural studies as one of the recent theories sees translation as a cultural activity (Munday, 2012). Descriptive Translation Studies is another theory which shows that translation is a part of literature, which focuses on the target language literature at the expense of the source language literature (Munday, 2012). Finally, some other theories describe translation with reference to some other aspects, such as discourse analysis, ideology, and socio-politics. 
It is obvious from the above explanation that approaches to translation have proposed different viewpoints in relation to the translation process due to their different understanding to it.

\section{Translation Problems}

Different classifications of translation problems have been proposed by translation theorists and scholars based on their perceptions on how translation process is carried out and which problems and difficulties arise in the process. One of the key figures working with functionalist approaches to translation is Christina Nord (1997, p. 64) who points out that "translation problems may be categorized as pragmatic, cultural, linguistic or text-specific". This research follows her classification to deal with problems encountered by translators while translating political texts. Therefore, the rest of this section will explain these four translation problems in detail.

1. Linguistic problems: the differences between the original and the target languages create linguistic difficulties. No two languages, to a great extent, are identical, since languages usually differ in terms of grammatical constructions, idiomatic expressions, and conditions.

2. Cultural problems: refers to the difference in expressing diverse ideas and approaching particular texts. For example, there is difference between the English pattern for an instruction manual and the French one, or a culture may use a particular categorization for types of animals while the other may not.

3. Pragmatic problems: pragmatic issues point to any problems concerning time, place and context. The most effective way to represent pragmatic issues is by the way of state institutions which names and associations are not the same in two different cultures (e.g., American State Departments vs. British Ministries).

4. Text specific problems: text particular issues are connected to a specific text. In other words, there are some problems and difficulties that are found in a particular text and not in other texts. For instance, The Kurdish General Power of Attorney text, as a legal document, is written in one paragraph without having any sections and subsections, while in in the UK, it is divided into several sections and subsections.

Every translation issue can be solved. You should know how to find the solution. Linguistic problems can be dealt with by the way of using dictionaries, language databases and other linguistic tools (Nord, 1997). Cultural difficulties can be tackled through comparing with parallel texts. For instance, when there is need to translate a marriage contract from the UK, the first thing that you have to do is to find 
a marriage contract sample in your target language. That is why it is recommendable to develop a set of parallel texts for every plan (Nord, 1997). Pragmatic issues can be fixed with reference to the translation brief or through speaking directly with the client (Nord, 1997). And, lastly, translators are able to overcome the text specific issues by means of employing their creativity.

\section{Specialized Translation}

Specialized translation is a notion applied to fields and areas that require comprehensive knowledge, precision and awareness in terms of terminology and grammatical structure in order to translate a specialized text properly. To this end, qualified specialized translators have to attend and participate in specific translation courses to obtain university degrees in a particular area or domain, such as legal translation, political translation, medical translation, science translation, and so on.

Recent research in the field of translation theories illustrate that most of the scholars (Schäffner, 2000; Neubert, 2000 \& Kelly, 2005) consider specialized translation skills as fundamental since they enable translators to apprehend and investigate the original texts perfectly and solve the problems that will emerge in the translation process.

Furthermore, translators have the ability to provide well translated texts in those fields that they are specialists in. In addition, each particular area has its own characteristics (Bowker \& Pearson, 2002). Hence, there are some linguistic items that make considerable contributions in the production of language for specific purpose, such as specialized terminology, collections and stylistic features.

There are various kinds of specialized translation, for instance, literary translation, legal translation, political translation, commercial translation, media translation, scientific translation, medical translation, technical translation...etc. in each of these fields, the texts have their own specific terminologies, idiomatic expressions and grammatical structures, which are not the features of the nonspecialized texts.

\section{Features of Political Language}

Political and diplomatic languages are part of the group of distinctive languages employed in the social sciences and are thus strongly connected to the tradition of "political opinion" (Sárosi-Márdirosz, 2014). Each of the two kinds specialized terminologies - is strongly connected with rhetoric, as the terminological origin of several verbal genres can be found in these specific languages (SárosiMárdirosz, 2014). 
Political language terminology is linked to the language of political theory, because this terminology contributes in raising the query that has been widespread concerning the relation between the person and community (Sárosi-Márdirosz, 2014). This is also associated with political hypothesis. $\mathrm{P}$ jargon is frequently utilized to work out the expressive hypotheses of political situation, also (like social analysis, the concepts of justice, law, etc.). Without political language, elaborating state theories would not have been achievable, and notions like "good governance" or "right form of government" might not have been developed. The definition of political thoughts (doctrines, philosophies, and policy programs and goals) is as well a significant scope for political language demonstration. Political terms include the following performances:

- Expressive performance, this implies that it conveys goals ingrained in the genuine political sphere.

- Objective performance, which means that it has fair and impartial rational for affecting people in their feelings, mind, thereby their behavior.

- Symbolic performance, which means that political symbols express the thoughts and feelings.

Assuming that we need to indicate the nature of the wording of political texts, it is valuable to look at what forms the center of political texts are based on. These domains of a political content can be: influence, thinking, misdirection or indeed hustling, all of which need particular language utilization. The eloquent discourse has a reason of persuading the gathering of people to assent with a thought or conclusion put forward by the speaker. One can deliver a successful powerful discourse in case he/she structures the debates as the settlement for an issue (Hart, 2000). The primary task of the author or the speaker is to persuade the gathering of people that a specific issue matters to them, and after that they must be persuaded that the speaker or author has the way for tackling the issue. There are various terminologies that influential speeches can come in, for example, pitches deals, discussions and political procedures. Passionate and/or coherent demands may be used in powerful speeches. Components such as body language, the eagerness of the community of onlookers, and the atmosphere in which the discourse is offered, all influence the accomplishment of an aim or purpose of the influential discourse.

It is not possible to investigate political terms separately; the entire sentence and even the whole debate must be taken into account in their analysis. When the terms are examined, we have to do so in their contextual frame, we must organize them in expressions and sentences. The main role of these words is not to explain something but to establish a relationship; this actuality of the matter is what makes the 
distinction among these terms and the rest of the dictionary (Hart, 2000, p. 104, cited in Sárosi-Márdirosz, 2014, p. 168).

\section{Political Language and Translation}

Firmly related texts are one of the characteristics that the political system is made of, so when working on establishing a new text (e.g., translations) "its coherence with the rest of the political texts" must be highly focused on (Sárosi-Márdirosz, 2014). Political terminology for instance, party of a contract, death-penalty and some non-terminological elements like regarding, breaking a contract can confirm this coherence. Non- jurists may find it difficult to understand the political texts as this coherence is also contributed by the tradition of the political texts. The reason is the juridical system is as logical system and the texts of which strive to get away from complexity and tough descriptions that are beyond the abilities of ordinary individual to comprehend, that might need to make further research so that it is clear enough. The defined range of these texts can illustrate the use of long phrases that bring about a tough responsibility for the translators to work on. In order for these texts to be understood someone must interpret them.

Strong complexity of the source text such as: act or contract, deed of foundation or statute, etc. is one of the issues that a translator might face (SárosiMárdirosz, 2014). Even though this notion contradicts the logical feature of the political texts, unskillfulness or lack of knowledge of those who have written the texts results in translators often encountering these problems (Sárosi-Márdirosz, 2014). Encountering problems and difficulties related to the act of translation can make a translator an interpreter, whereas facing the problems related to the content of the paper does not. The lack of lucidity caused by the differences between the two language systems makes the problem even more significant. Translators have to avoid creativity and try to embed the traditional specialized language within the translation process (Sárosi-Márdirosz, 2014). In the present research, the specialized language refers to the language of a field or range that reflects part of reality which, at the end, is the research domain of a group of specialists (Kurtán, 2003, p. 50).

Tackling specialized language is never an easy job for translators, as they could possibly use other linguistic choices, or they might not approve the prevailing words and expressions. Another hardship that translators could challenge is that the documentation sources could not be accessible to them (Várnai, 2006, p. 48 cited in Sárosi-Márdirosz, 2014). In translating political texts, adopting the existing source language terms and expressions by the translators is extremely crucial, due to the fact that this will be the code of political translation and the device of coherent texts (Sárosi-Márdirosz, 2014, p. 169). In order to obtain and establish the most appropriate equivalent between the original and the target texts, translators should pay a very 
close attention to many political, linguistic and cultural features when they come across new notions and ideas in the process of translation.

Nida (1964 \& 2004) remarks that language can be considered as a component of culture, and in reality, it is the most complicated set of traditions that can be found in any culture. Language is the mirror of the culture, gives the way to get familiarity with the culture, and in many regards creates a cultural model. Sárosi-Márdirosz (2014) states that the following techniques might be used by translators in order to convey some cultural certain items and to reflect a particular cultural model:

- Omission: when a part of a text is either deleted or reduced.

- Expansion: changing original implicit information into explicit information in the main body or in footnotes or a glossary.

- 'Exoticism': replacing original text's stretches of slang, dialect or nonsense vocabularies by rough equivalents in the target language.

- Updating: Replacing obsolete or unclear information by modern equivalent.

- Situational equivalence: Embedding more familiar contexts instead of the original one.

- Creation: Replacing the original text with a text that keeps the important message, ideas, and functions of the original one.

\section{Methodology}

This section discusses certain aspects pertaining to the research methodology that are adopted in the present study. First and foremost, this study is a qualitative research. The tool that is utilized to gather data in the present research is document analysis.

As far as the materials are concerned, the text that has been chosen for this research is the political text. The actual number of texts which have been gathered for the research consists of four texts, two English source texts and two Kurdish target texts. Although dealing with four texts are not entirely satisfactory for the comparison between English and Kurdish languages in the translation process, the main reason lies with the word count limitation in the study. Concerning the way of gathering texts, the researcher has received them from the translator who translated the English texts broadcasted in Reuters News Agency into Kurdish for a TV channel, in which the translations were broadcasted.

Regarding the procedure, in order to analyze the collected data, the texts are investigated based on the Nord's classification of translation problems (1997): pragmatic, cultural, linguistic or text-specific, in order to find the translation problems and difficulties in the English source texts and how they have been translated into Kurdish. Furthermore, after analyzing and identified each problem, the possible solutions are presented. 


\section{Findings and Discussion}

This section is devoted to present the main findings and analyze them. It is obvious that the setting in which the source text is created is more or less unlike that of the translation text in terms of location, time, audience, medium, motive and aim of message (Nord, 1997). As a result, the circumstances of the English texts where they work to performance its purposes are not the same as its target text accomplishing it purposes in the Kurdistan region. Due to the differences in terms of the purpose of production between the source and the target texts, the translators encounter four types of the problems, namely pragmatic, cultural, linguistic or text-specific (Nord, 1997). Below are the problems that the translator faces while s/he is translating the English political texts into Kurdish:

\section{Linguistic Problems}

English and Kurdish are two different languages, and they belong to different families or groups. The English language, for instance, belongs to Germanic group of languages, while Kurdish belongs to the Indo-European languages. This difference between the two languages poses problems in the translation process in some respects, such as word order, passivation, etc. which ultimately affects the capability of retaining meaning.

To exemplify the linguistic problems, here is an example taken from source text one (ST1) and target text one (TT1) which shows the differences in terms of word order between English and Kurdish languages. More specifically, the English has the (SVO) word order, while the Kurdish has (SOV) in which the verbal element is shifted to the end.

Farid Raeed, an official at the Ministry of Health, said one civilian was killed in the blast and seven others had been brought to two hospitals in the capital.

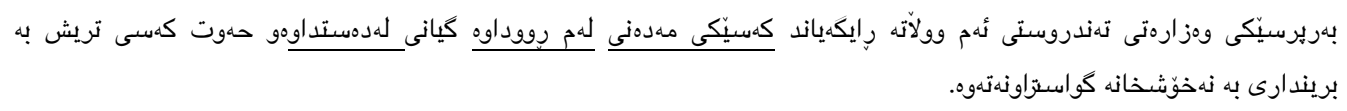

To solve problems in this type, translators should translate this sentence based on the word order of the target language so as to be readable and have a clear meaning as the translator has done in the above example in the Kurdish language text.

\section{Pragmatic Problems}

These problems that appear stem from the fact that the commutative situation of the source text is different from that one in which the translation text is produced. 
Therefore, the translator encounters several difficulties regarding pragmatics in translating the texts. Translating proper names is considered as a problem in this kind, which arises very often in the English texts. To support this opinion, Nord (1997) claims that translating proper names is difficult and problematic. Here is an example taken from source text two (ST2) and target text two (TT2) (see in appendix):

The $62^{\text {nd }}$ Annual disarmament conference organized by the United Nations held its closing ceremony on Friday (September 11) in Mexico City, Mexico.

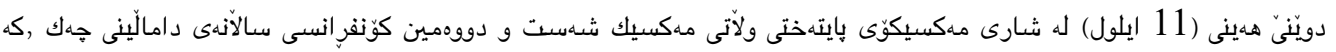

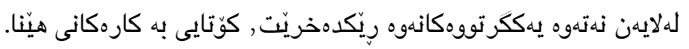

The two names 'Mexico City, and Mexico' are names of places. In the target language, both names are used. So, the translator should be aware of the proper names and convey them into the target language according to the way it is used in the target culture, because some proper names have different names in different cultures, for instance, the name of 'Poland' in Kurdish is the same, but in Persian language the name 'Lhustan' is used instead of 'Poland'.

\section{Cultural Problems}

Culture is the mirror of society. It varies from one society to another. Sometimes even in the same society, different cultural items can be noticed. Since English and Kurdish are two different cultures, the translators encounter difficulties when they translate an English text into Kurdish or the vice-versa. What is more, cultural differences pose greater difficulties than linguistic differences in the translation practice. Here is an example taken from ST1 and TT1 which contains the name 'International Security Assistance Force' which belongs specifically to the USA country or culture.

"Six to seven civilians were wounded as a result of the blast and two ISAF (International Security Assistance Force) were killed.

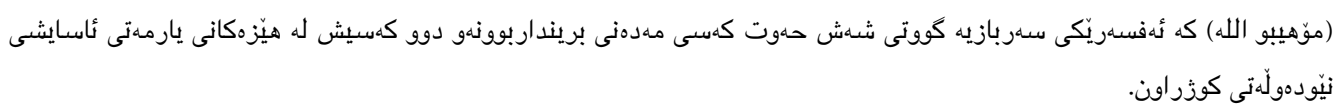

To overcome this translation difficulty, the translator has two options to reproduce the name in the target language. In the first choice, the most appropriate equivalent is used to the name which has its equivalent meaning, 'International Security Assistance Force'. Secondly, rewording is the second choice employed in the 
translation process to solve the problem. In addition to that, political ideology could be another issue related to cultural problems. This usually happens when there is absence of a political concept in the target language and secondly when the concept stands opposite to a political ideology.

\section{Text-Specific Problems}

These problems refer to those difficulties that appear only in that text translated from language to another, and they may not be found in another text, hence they are called text-specific problems. For instance, ST2 includes a paragraph consists only of one sentence, which might be problematic in terms of paragraphing for the translator if $\mathrm{s} / \mathrm{he}$ produces a paragraph of sentence in the Kurdish language. Here is the example:

Conference Chair Charles Hitchcock emphasized the importance of their mission.

In this case, the translator should arrange this paragraph according to the conventions of the target language, as it has been done in the Kurdish translated text.

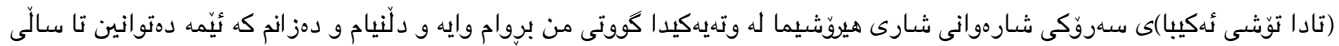

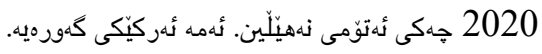

\section{Conclusions}

The characteristics of political language make it a difficult task for translators to translate it accurately. This stems from the fact that when politicians speak, they do not attempt to convey their messages to foreign addressees and/or the political speech, mostly, is loaded with overtones. That is why translators cannot translate properly and present the same effect on target text addressees that the source text has on its audiences. The findings of the study demonstrate that the main responsibility that translators should take in translating political texts is transferring the basic meaning of the original text. Translators must have knowledge about the exact historical, cultural and political influence and try to show it in the translation version to make the same influence. Translators have to use a clear, rather than a fancy, language in order for the text to have the same desired effects. They should also know and learn the proper standard of political language. Thus, translating political texts requires mastery and knowledge in several aspects, namely linguistic and cultural, political and historical background of both languages, and the events where the text is produced. 


\section{References}

Altun, M., \& Sabah, R. (2020). The effect of cooperative learning strategies in the enhancement of EFL learners' speaking skills. Asian EFL Journal, 27(2), 144-171.

Ali, F.S. (2021). Overlap and repair of turn-taking system during collaborative oral peer-feedback in an EFL writing course. International Journal of Social Sciences \& Educational Studies, 8(2), 128-134.

Ahmad, R. S. \& Meena, R. S. (2021). Assessing the level of students' exposure to english language in ELT department at Tishk International University-Erbil, Iraq. Review of International Geographical Education (RIGEO), 11(5), 29192929.

Bassnett, S. (2002). Translation studies. London and New York: Routledge.

Barzani, S. H. H. (2020). The perceptions of EFL teachers and students on the use of short stories to enhance reading comprehension. Asian EFL Journal, 27(3.1), 325-341.

Barzani, S. H., Aslam, M. Z., \& Aslam, T. (2021). The role of technology in ELL classes in Turkish Republic of Northern Cyprus. IJOLE-International Journal of Language Education, 5(2), 30-39.

Bowker, L., \& Pearson, G. (2002). Working with specialized language: A practical guide to using corpora. London: Routledge.

Catford, J.C. (1965). A linguistic theory of translation. London: Oxford University Press.

Fuad, H. A., \& Ulker, V. (2020). The effect of inquiry-based approach on the development of reading and writing skills of university EFL students. Asian EFL Journal, 27(2.3), 84-100.

Hatim, B., \& Munday, J. (2004). Translation: An advanced resource book. London/New York: Routledge.

Kelly, D. (2005). A handbook for translator trainers: A guide to reflective practice. Manchester: St. Jerome.

Kurtán, Zs. (2003). Szakmai nyelvhasználat [Language for Special Purposes]. Budapest: Nemzeti Tankönyvkiadó.

Long, J. (2013). "Translation Definitions in Different Paradigms". Canadian Social Science, 9/4, 107-115.

Munday, J. (2012). Introducing translation studies. London/New York: Routledge.

Neubert, A. (2000). Competence in Language, in Languages and in Translation, in Schäffner C., \& Adab, B. (eds.) Developing translation competence. Amsterdam/Philadelphia: Benjamins, pp 3-18.

Nida, E.A. (1964/2004). Principles of Correspondence, in Venuti, L. (ed.) Translation studies reader. London: Routledge, pp. 153-167.

Nord, C. (1997). Translating as a purposeful activity. Manchester/Kinderhook: St Jerome.

Omer, Y. (2016). Equivalence as controversial concept in translation studies. Journal of Raparin University 4/12, 5-22.

Pym, A. (2009). Exploring translation theories. London: Routledge. 
Sárosi-Márdirosz, K. (2014). Problems related to the translation of political texts. Acta Universitatis Sapientiae, Philologica 6/2, 159-180.

Schäffner, C. (2000). Running before walking? Designing a translation programme at undergraduate level, in Schäffner, C., \& Adab, B. (ed.) Developing translation competence. Amsterdam: John Benjamins, pp. 143-156.

Schäffner, C. (2001). Annotated texts for translation: English-German. Clevedon: Multilingual Matters.

Vermeer, H. (1996). A Skopos theory of translation (Some arguments for and against). TEXT context: Heidelberg.

Zirak, H. C. K. (2021). Embodied learning implementation in EFL classroom: A qualitative study. International Journal of Social Sciences \& Educational Studies, 8(1), 51-58. 